\title{
The Causal Relationship between Economic Policy Uncertainty and Stock Returns in China and India: Evidence from a Bootstrap Rolling Window Approach

\author{
Xiao-lin Li ${ }^{*}$, Mehmet Balcilar ${ }^{* *}$, Rangan Gupta ${ }^{* * *}$ and Tsangyao Chang ${ }^{* * * * *}$
}

\begin{abstract}
This paper examines the causal link between economic policy uncertainty and stock returns in China and India, using bootstrap Granger full-sample causality test and sub-sample rolling window estimation. We use monthly data covering from 1995:02 to 2013:02 for China and 2003:02-2013:02 for India. The bootstrap full-sample Granger causality test suggests no evidence of any causality between economic policy uncertainty and stock returns for the two countries. However, taking structural changes into account, we assess stability of parameters of the estimated vector autoregressive (VAR) models. We find both the short-run and long-run relationships between economic policy uncertainty and stock return estimated using full-sample data are unstable over the sample period. This suggests that full-sample causality tests cannot be relied upon. We turn to propose a time-varying (bootstrap) rolling window approach to revisit the dynamic causal relationship between the two variables. Using a rolling window of 24 months, we do find that there are bidirectional causal relationships between stock returns and EPU for several sub-periods in China and India. However, the association between EPU and stock returns is, in general, weak for these two emerging countries. These findings have important implications for policy makers as well as investors.
\end{abstract}

Keywords: Economic Policy Uncertainty; Stock returns; Rolling Window; Bootstrap; Time-Varying Causality;

JEL Classifications: C32, G12, G18

\footnotetext{
Department of Finance, Ocean University of China, Qingdao, China. E-mail: smileman2004@126.com.

** Department of Economics, Eastern Mediterranean University, Famagusta, Turkish Republic of Northern Cyprus, via Mersin 10, Turkey. Email: mehmet@ mbalcilar.net.

*** Corresponding author. Department of Economics, University of Pretoria, Pretoria, 0002, South Africa. Email: rangan.gupta@up.ac.za.

***** Department of Finance, Feng Chia University, Taichung, Taiwan. Email: tychang@ @cu.edu.tw.
} 


\section{INTRODUCTION}

Government policy-makers often contribute to massive economic uncertainty when they cannot agree or change economic policies frequently. The resulting policy-related economic uncertainty, which we refer to as economic policy uncertainty (EPU), may cost the overall economy millions of jobs, hold back the economic recovery or elicit the stock markets slumping. Over the past decades, substantial studies have been undertaken mainly focusing on the negative effects that EPU has on inflation, investment, employment and economic growth (Marcus, 1981; Bernanke, 1983; Dixit, 1989; Rodrik, 1991; Aizenman and Marion, 1993; Bloom et al., 2007; Bloom, 2009; Bhagat et al., 2013). However, a key connection that arises here is: if EPU does have significant impacts on these economic fundamentals, then it would also be expected to have real impacts on stock market performance. Moreover, the modern finance theory reveals that stock price is actually the sum of the net present value of all expected future dividends. In this regard uncertainty about economic policies that fuels market participants' pessimistic considerations about expected future dividends and/or discounts rates probably leads to a decline in stock prices, while on the other hand certain economic policies that help to restore market confidence often stimulate positive investment reactions and finally cause an increase in stock prices. That is, the performance of stock market is likely to be negatively affected by EPU. However, it should be noted that EPU may have a positive effect on stock prices. The main rationale behind this is that economic policy-induced uncertainty would increase equity risk premium and hence lead to a higher stock price (Brogaard and Detzel, 2013). Stock market performance can also affect EPU in turn, since government policy-makers sometimes have to adjust policies in response to an increased volatility in the stock markets, and consequently the more volatile the stock markets, the higher uncertainty about economic policies would be (Antonakakis et al., 2013).

However, unlike much earlier attention to the effects of EPU on inflation, investment, employment and economic growth, special attention has just been given to the relationship between EPU and stock market performance (proxied by stock price or stock return) exactly after the recent global financial crisis of 2008. Ozoguz (2009) finds a negative linkage between 
stock returns and the level of economic uncertainty which is based on the state probabilities estimated from two-state regime-switching regime models of aggregate stock market returns. Dzielinski (2012) constructs an indicator of economic uncertainty from the search volume index (SVI) for the word "economy" provided by Google Trends and finds that a high degree of economic uncertainty is followed by a significant drop of stock returns. Pástor and Veronesi (2012) find that government policy uncertainty which is defined as the variance of policy change is negatively associated with stock market returns. In particular, since Baker et al. (2012) constructed a new measurement of EPU, the empirical studies concentrating on such a relationship have been greatly encouraged. Sum (2012a) develops a VAR analysis using the EPU index of the United States and shows that an increase in EPU Granger-cause the market returns to drop. Sum (2012b) shows that the changes in EPU negatively affect all stock market returns in the Euro zone, Croatia, Norway, Russia, Switzerland, Turkey and Ukraine. Bhagat et al. (2013) document a negative correlation between the Bombay Stock Exchange (BSE) index and EPU in India. Economic conditions have also been taken into account to the effects of EPU on the performance of stock market, as EPU is an economically-important risk factor which commands a higher risk premium especially under bad economic conditions. Pástor and Veronesi (2013) present that stock returns are more volatile and more correlated when EPU is higher and economic conditions are weaker. Brogaard and Detzel (2013) support that the effect of EPU on stock returns varies with the macroeconomy. They conclude that higher EPU causes lower contemporaneous stock returns but results in higher future returns. Antonakakis et al. (2013) construct a dynamic conditional correlation (DCC) model consisting EPU index and stock returns series for the United States and find that increased EPU leads to lower stock returns and in turn an increased stock market volatility leads to increased EPU. Kang and Ratti (2013) document that for the United States real stock returns decline in response to an unexpected increase in EPU. Additionally, studies conducted by Sum (2012c, 2012d) suggest the negative spillover effects that EPU in the United States has on stock market returns in Brazil, India, Russia and Association of Southeast Asian Nations (ASEAN).

This paper makes a contribution to revisit the causal relationship between EPU and stock market returns for two emerging market economies: China and India. As we know, China has 
been the world's second largest economy since 2010, while India has also been one of the largest and fastest growing economy in the world with an average economic growth rate of $7.28 \%$ during $2004-2013^{1}$. As a consequence, their economic performance, such as government policy conditions and stock market performance, has never been more associated with the global financial market than it is today. Moreover, the economic competition and cooperation between the two economies have never been more delicate than they are today. However, it should be noted meanwhile that the Indian economy has run into deep structural problems due to increased policy uncertainty and the lack of adequate economic reforms since 2004, which could inevitably affect stock market performance; similarly, uncertainty about the direction of Chinese economic policy has also roiled financial markets over the past years. Based on these economic backgrounds, we are subsequently motivated to investigate the causal relationship between EPU and stock returns for the two merging market economies. Besides, the newly introduced EPU index constructed by Baker et al. (2012) is employed in this study, and just because of availability of the EPU index, the sample ranges from 1995:02 to 2013:02 in China and from 2003:02 to 2013:02 in India. The sample periods cover well the significant increases in policy-induced economic uncertainty and remarkable volatilities in stock markets of China and India, which is of great help to mirror the dynamics of EPU and stock returns for the two countries.

This paper makes the other contribution to existing literature by taking into account the time variation in the causal links between EPU and stock returns with bootstrap Granger non-causality test and rolling-window sub-sample estimation. Empirical literature examining causality between two time series may suffer from inaccurate results when the underlying full-sample time series have structural changes (Balcilar et al., 2010). In the presence of structural changes, the dynamic links between the two series will show instability across different sub-samples (Balcilar et al., 2010). This can be addressed by allowing the causal relationship between the two series to be time-varying instead of using full-sample data that assumes the single causality holds in every time period. The time-varying nature that may exist

\footnotetext{
${ }^{1}$ The average growth rate of India over the past ten years is calculated using data of GDP at constant prices available with the international Monetary Fund (IMF).
} 
in the causal link between EPU and stock returns of China and India has been taken fully into consideration in this paper by using bootstrap sub-samples rolling window estimations. Instead of just testing for causality on the full-sample which assumes a permanent causal relationship, we also test for causality on the rolling sub-sample with a fixed-size window, thus allowing us to capture structural changes in the model and the evolution of causality between sub-periods. In light of this, our paper is starkly different from the existing literature which, in general, only considers full-sample causality, and unlike our study is susceptible to misleading results and conclusions in the presence of parameter instability due to structural breaks in the relationships.

This study proceeds as follows. Section 2 explains the methodology. Section 3 describes the corresponding data. Section 4 presents the empirical results and policy implications. Section 5 concludes.

\section{METHODOLOGY}

\subsection{Bootstrap Full-sample Causality Test}

The purpose of this paper is to analyze the causal relationship between EPU and stock returns for China and India. We thus make use of the Granger non-causality test in the bivariate VAR framework proposed by Balcilar et al. (2010). In general terms, standard causality test statistics for joint restriction and standard asymptotic properties include the Wald, Likelihood Ratio (LR) and Lagrange Multiplier (LM) statistics. However, according to Sims et al. (1990) and Toda and Phillips (1993, 1994), when the underlying time series data in levels estimation of VAR models is non-stationary, these test statistics may not have standard asymptotic distributions. Toda and Yamamoto (1995) propose a modified Wald test by estimating an augmented VAR model with I (1) variables to obtain standard asymptotic distribution for the Wald test. However, Shukur and Mantolos (1997b) use Monte Carlo simulations to show that the modified Wald test does not have correct size in small and medium size samples. Nevertheless, Shukur and Mantalos (1997a) suggest that improvement (in terms of power and size) can be achieved by using the residual based bootstrap (RB) method critical values. Moreover, the excellent performance of the RB method over standard asymptotic tests, 
regardless of cointegration or not, has been confirmed in a number of Monte Carlo simulations studies (Mantalos and Shukur, 1998; Shukur and Mantalos, 2000; Mantalos, 2000; Hacker and Hatemi-J, 2006; Balcilar et al., 2010). Especially, Shukur and Mantalos (2000) prove that small sample corrected LR tests exhibit relatively better power and size properties, even in small samples. As a consequence, based on these findings, this paper resorts to the RB based modified-LR statistic to examine causality between EPU and stock returns for China and India.

In order to demonstrate the $R B$ based modified- $L R$ causality test, we consider the bivariate $\operatorname{VAR}(p)$ process as follows:

$$
y_{t}=\phi_{0}+\phi_{1} y_{t-1}+\ldots \ldots \ldots \ldots+\phi_{p} y_{t-p}+\varepsilon_{t}, \quad t=1,2, \ldots \ldots \ldots, T
$$

where $\varepsilon_{t}=\left(\varepsilon_{1 t}, \varepsilon_{2 t}\right)^{\prime}$ is a white noise process with zero mean and covariance matrix $\sum$. The optimal lag length $p$ is determined by the Schwarz Information Criteria (SIC) in this study. If $y_{t}=\left(y_{1 t}, y_{2 t}\right)^{\prime}$ is split into two sub-vectors, $y_{1 t}$ and $y_{2 t}$, the equation (1) can accordingly be represented as:

$$
\left[\begin{array}{l}
y_{1 t} \\
y_{2 t}
\end{array}\right]=\left[\begin{array}{l}
\phi_{10} \\
\phi_{20}
\end{array}\right]+\left[\begin{array}{ll}
\phi_{11}(L) & \phi_{12}(L) \\
\phi_{21}(L) & \phi_{22}(L)
\end{array}\right]\left[\begin{array}{l}
y_{1 t} \\
y_{2 t}
\end{array}\right]+\left[\begin{array}{l}
\varepsilon_{1 t} \\
\varepsilon_{2 t}
\end{array}\right]
$$

where $y_{1 t}$ and $y_{2 t}$ indicates the growth rates of EPU and stock prices respectively. In the empirical section, the latter variable refers to as stock returns. $\phi_{i j}(L)=\sum_{k=1}^{p+1} \phi_{i j, k} L^{k}, i, j=1,2$ and $L$ is the lag operator defined as $L^{k} x_{t}=x_{t-k}$.

Based on Eq. (2), the null hypothesis that stock returns does not Granger cause EPU is tested by imposing the restriction, $\phi_{12, k}=\mathbf{O}$ for $k=1,2, \ldots ., p$. Similarly, the null hypothesis that EPU does not Granger cause stock returns is tested by imposing the restriction, $\phi_{21, k}=\mathrm{O}$ for $k=1,2, \ldots . ., p$. As discussed, the full-sample causality tests in this paper are relied upon $R B$ based $p$-values and modified- $L R$ statistics. If the first null hypothesis, $\phi_{12, k}=\mathrm{O}$ for $k=1,2, \ldots \ldots, p$ is rejected, then there is a significant causality running from stock returns to the growth rates of EPU in China and (or) India. This means that stock returns 
can predict movements in EPU. In like manner if the second null hypothesis, $\phi_{21, k}=\mathrm{O}$ for $k=1,2, \ldots ., p$ is rejected, then stock market returns is caused by movements in EPU. This provides evidence for China and (or) India that policies that bring about decrease in EPU would most likely improve stock market performance, which would have important implications for the two countries, especially for China whose stock market is experiencing a gloomy performance.

\subsection{Parameter Stability Test}

The full-sample causality tests usually assume that parameters of the VAR model used in testing are constant over time. However, when the underlying full-sample time series have structural changes, the assumption is probably violated. The results from the full-sample causality tests would become invalid and hence the causal links between series would show instability (Balcilar and Ozdemir, 2013). Granger (1996) stresses the issue of parameter non-constancy as one of the most challenging issues faced by recent empirical studies. As a result, tests for short-run and long-run parameter stability should be conducted in this paper.

We use the Sup-F, Mean-F and Exp-F tests developed by Andrews (1993) and Andrews and Ploberger (1994) to investigate the short-run parameters stability. Nevertheless, it is noted that when the underlying variables in levels are cointegrated, the VAR model in first differences is misspecified unless it allows for error-correction. Hence, it is very essential to test for cointegration and parameter stability of the long-run relationship. This is achieved based on different structural changes and parameter stability tests on the long-run relationship estimated using the Fully Modified ordinary least squares (FM-OLS) estimator of Phillips and Hansen (1990). The $L_{c}$ test proposed by Nyblom (1989) and Hansen (1992) is mainly applied to investigate the long-run parameters stability. Particularly when the underlying series are $I$ (1), it also serves as a test of Cointegration (Balcilar et al., 2010). In the empirical section, we employ the $M Z_{a}$ test developed by $\mathrm{Ng}$-Perron (2001) and the KPSS test proposed by Kwiatowski et al. (1992) to determine whether the two variables in levels, EPU and stock prices, are $I(1)$ or not. 
The above parameter tests exhibit non-standard asymptotic distributions. By means of the parametric bootstrap procedure, Andrews (1993) and Andrews and Ploberger (1994) report the critical values and $p$-values for the non-standard asymptotic distributions of these tests. ${ }^{2}$ Besides, according to Andrews (1993), 15 percent trimming from both ends of the sample is required for the Sup-F, Mean-F and Exp-F. Hence, the tests are applied to the fraction of the sample in $(0.15,0.85)$. With respect to the $L_{c}$ tests, they are computed in the current paper for equations and VAR system separately by applying the $F M-O L S$ estimator.

\subsection{Sub-sample Rolling-window Causality Test}

Structural changes can be identified beforehand and incorporated into the estimation using several techniques such as sample splitting and the use of dummy variables. However, these techniques impose a disadvantage of pre-test bias. In order to overcome the parameter non-constancy and avoid pre-test bias, this study is therefore proposed by using the rolling-window sub-samples Granger causality test based on the modified bootstrap estimation. ${ }^{3}$ Two important reasons justify the use of the rolling estimation. First, the rolling window agrees with the fact that the causal relationship between variables changes over time. Second, the rolling estimation can observe instability across different sub-samples due to the presence of structural changes.

Following Balcilar et al. (2010), the rolling window technique is based on fixed-size sub-samples rolling sequentially from the beginning to the end of the full-sample. Specifically, given a fixed-size rolling window including $l$ observations, the full-sample is converted to a sequence of $T-l$ sub-samples, that is, $\tau-l+1, \tau-l, \ldots, \mathrm{T}$ for $\tau=l, l+1, \ldots, \mathrm{T}$. The $R B$ based modified- $L R$ causality test is then applied to each sub-sample, instead of estimating a single causality test for full sample. Possible changes in the causal links between EPU and stock returns for China and India are intuitively identified by calculating the bootstrap $p$-values of observed $L R$-statistic rolling through T- $l$ sub-samples. More importantly, the magnitude of the effect of EPU on stock returns as well as that of stock returns on EPU is also assessed in this

\footnotetext{
2 Specifically, the critical values and $p$-values are obtained using asymptotic distribution constructed by means of Monte Carlo simulations using 2000 samples generated from a VAR model with constant parameters.

${ }^{3}$ For technical details of the bootstrap test see Balcilar et al (2010), appendix.
} 
study. The impact of EPU on stock returns is defined as the average of the entire bootstrap estimates deriving from the formula $N_{b}^{-1} \sum_{k-1}^{p} \hat{\phi}_{21, k}^{*}$, with $N_{b}$ representing the number of bootstrap repetitions; in similar manner, the impact of stock returns on EPU is obtained from the formula $N_{b}^{-1} \sum_{k-1}^{p} \hat{\phi}_{12, k}^{*}$. Both $\hat{\phi}_{21, k}^{*}$ and $\hat{\phi}_{12, k}^{*}$ are bootstrap estimates from the VAR models in Eq. (2). The 90-percent confidence intervals are also computed, where the lower and upper limits equal 5th and 95th quantiles of each of the $\hat{\phi}_{21, k}^{*}$ and $\hat{\phi}_{12, k}^{*}$ respectively (Balcilar et al., 2010).

The accuracy and performance of rolling window estimation depends on the increment interval of each regression and the window size $l$. Small intervals such as one are recommended as they provide more detailed transition since it maximizes the total number of rolling regressions. The window size $l$ is the parameter that controls the number of observations covered in each sub-sample and also the precision of estimates. A large window size may improve the accuracy of estimates but may reduce the representativeness especially in the presence of heterogeneity. However, a small window size reduces heterogeneity and improves the representativeness of parameters but may reduce parameter accuracy by increasing the standard errors of estimates. Consequently, the window size should be set to balance the trade-off between representativeness and accuracy.

No consistent criterion is available for us to select the window size in rolling window estimation (Balcilar et al., 2010). Pesaran and Timmerman (2005) assess the window size under structural change according to root mean square error. They show that the optimal window size depends on persistence and size of the break. Based on their Monte Carlo simulations, they argue that the bias in autoregressive (AR) parameters are minimized with a window size as low as 20 when there are frequent breaks. Two conflicting demands have been taken into account when we choose the suitable window size. First, the degree of freedom that relates to the precision of parameter estimates requires for a larger window size; second, the presence of multiple structural changes that possibly increases the risk of including some of these multiple shifts in the windowed sample claims for a smaller window size. Therefore, a small window size of 24 months is chosen in this study (this excludes the observations required 
for lags and hence is the actual number of observations in the VAR). As for the issue of inaccurate estimates as a result of the selected small window size, it can be addressed by the bootstrap technique employed in the rolling estimation for better precision.

\section{DATA}

For an assessment of the causal links between EPU and stock returns in China and India, we first obtain the monthly EPU indices of the two countries from Baker et al. (2012) ${ }^{4}$ and the monthly stock price series from the International Financial Statistics maintained by the International Monetary Fund. To measure policy-related economic uncertainty for India, Baker et al. (2012) construct an index from two types of underlying components, namely, newspaper coverage of EPU and disagreement among economic forecasters as a proxy for EPU. While for China, Baker et al. (2012) construct a scaled frequency count of articles about policy-related economic uncertainty in the South China Morning Post, which is, Hong Kong's leading English-language newspaper. The method, thus, follows the news-based indexes of economic policy uncertainty for the United States and other countries. Secondly, all the original data is processed by taking natural logarithms, to correct for potential heteroscedasticity and dimensional difference between series. Thirdly, we take first-differences of the variables and multiply by 100 to get month-on-month growth rates of EPU and stock prices in percentages. Note that, the growth rates of stock prices (SP) are defined as stock returns (SR) in this paper. Since we work with the growth rates (as we are interested in stock returns) our effective sample for China spans from 1995:02 to 2013:02 and spans from 2003:02 and 2013:02 for India. Though the sample periods of China and India differ from each other because of the availability of the EPU index, they both cover well the significant increases of policy-induced economic uncertainty and the remarkable volatilities in the stock markets, which is of great help to mirror the dynamics of EPU and stock returns.

The plots of stock returns and the growth rates of EPU for China and India are presented in Appendix 1. In general China's EPU is more volatile than India's. Especially during the Asian

\footnotetext{
${ }^{4}$ The EPU indices of China and India are available on the Economic Policy Uncertainty Index website http://www.policyuncertainty.com.
} 
financial crisis and the global financial crisis EPU shows the most drastic fluctuations in China. For India, relatively severe fluctuations happened in 2003-2004 and in the global financial crisis of 2008. With respect to stock return, the Indian stock market has shown a much better performance than China's at least over the past decade. Since 2003 India rode its way to an enviable bull market except for a short crash in 2008. For the case of China, over the past two decades a frustrating performance has occupied about half of the time. Nevertheless, overall, stock returns in the two countries are associated with movements in EPU for several sub-periods.

\section{EMPIRICAL RESULTS}

Tests for stationarity of the underlying data are first conducted using the $M Z_{a}$ test developed by Ng-Perron (2001) and the KPSS test proposed by Kwiatowski et al. (1992).

Table 1 panel $\mathbf{a}$ and $\mathbf{b}$ report the corresponding results for intercept, as well as intercept and linear trend respectively. The $M Z_{a}$ statistics fail to reject the null hypothesis of non-stationarity for all series in levels except for EPU in China while reject the null hypothesis when the series are in their first differences. The KPSS tests are able to reject the null hypothesis of stationarity for all series in levels while cannot reject the null hypothesis when the series are in their first differences. To sum up, the $M Z_{a}$ and KPSS test results show that stock prices and EPU for China and India are non-stationary process in levels but attain stationary in their first differences. This means that they are both integrated of the first order, i.e. $I(1)$, implying that cointegration test should be performed to decide whether the VAR models in first differences are misspecified by ignoring an error-correction term. 
Table 1a: Ng- Perron $M Z_{a}$ unit root test results

\begin{tabular}{|c|c|c|c|c|}
\hline \multirow[t]{2}{*}{ Series } & \multicolumn{2}{|l|}{ Level } & \multicolumn{2}{|c|}{ First differences } \\
\hline & Constant $^{\mathrm{a}}$ & $\begin{array}{c}\text { Constant } \\
\text { with trend }\end{array}$ & Constant $^{\mathrm{a}}$ & $\begin{array}{c}\text { Constant } \\
\text { with trend }\end{array}$ \\
\hline EPU for China & $-6.92715^{*}$ & -9.71476 & $-114430^{* * * *}$ & $-14729.9^{* * * *}$ \\
\hline SP for China & -0.63642 & -10.0595 & $-59.3196^{* * * *}$ & $-63.3683^{* * *}$ \\
\hline EPU for India & -3.00489 & -11.8260 & $-13.6979^{* *}$ & $-18.4379^{* *}$ \\
\hline SR for India & 0.31803 & -5.41991 & $-48.1276^{* * *}$ & $-50.1153^{* * *}$ \\
\hline
\end{tabular}

Table 1b: Kwiatkowski-Phillips-Schmidt-Shin (KPSS) unit root test results

\begin{tabular}{lcccc}
\hline Series & Level & \multicolumn{3}{c}{ First differences } \\
\cline { 2 - 5 } & Constant $^{\mathrm{a}}$ & $\begin{array}{c}\text { Constant } \\
\text { with trend }^{\mathrm{b}}\end{array}$ & Constant $^{\mathrm{a}}$ & $\begin{array}{c}\text { Constant } \\
\text { with trend }^{\mathrm{b}}\end{array}$ \\
\hline EPU for China & $0.778922^{* * *}$ & $0.130091^{*}$ & 0.063422 & 0.030793 \\
SP for China & $0.413124^{*}$ & $0.124315^{*}$ & 0.13131 & 0.054083 \\
EPU for India & $0.701079^{* *}$ & $0.169326^{* *}$ & 0.034434 & 0.034697 \\
SR for India & $0.36843^{*}$ & $0.156772^{* *}$ & 0.223763 & 0.036756 \\
\hline
\end{tabular}

Notes: ${ }^{* * * * *},{ }^{* *}$ and ${ }^{*}$ indicates significance at the 1,5 and 10 percent level respectively.

${ }^{\text {a }}$ This is a one-side test with null hypothesis that the series is stationary; 1,5 and $10 \%$ significance critical value equals $0.739,0.463,0.347$, respectively.

${ }^{\mathrm{b}}$ This is a one-side test with the null hypothesis that the series is stationary; 1,5 and $10 \%$ significance critical value equals $0.216,0.146,0.119$, respectively.

As we are interested in examining the causal relationship between stock returns and growth rates of EPU, bivariate VAR models consisting of the first-differenced log-levels of both EPU and stock prices are then constructed as Eq. (2). The optimal lag-lengths based on Schwarz Information Criterion $(S I C)$ are 1 and 2 respectively, for China and India. By means of the $R B$ based modified- $L R$ causality tests, the full-sample causality results are reported in Table 2. According to the bootstrap $p$-values, both the null hypotheses fail to rejected, indicating absence of any full-sample causal links between EPU and stock returns in China and India. This finding is greatly inconsistent with existing literature. For instance, Pástor and Veronesi (2012), Sum (2012a, b), Brogaard and Detzel (2013) and Antonakakis et al. (2013) argue that a unidirectional or bidirectional causal relationship exists between EPU and stock 
returns. This conflict has to do with the data examined and the methodology used, as well as the effect of structural changes.

Table 2: Full-Sample Granger Causality Tests

\begin{tabular}{lcccc}
\hline Tests & \multicolumn{2}{c}{$\begin{array}{l}\mathrm{H}_{0} \text { : EPU does not } \\
\text { Granger cause SR }\end{array}$} & \multicolumn{2}{c}{$\begin{array}{l}\mathrm{H}_{0} \text { : SR does not Granger } \\
\text { cause EPU }\end{array}$} \\
\cline { 2 - 5 } & Statistics & $p$-values & Statistics & $p$-values \\
\hline Bootstrap LR Test for China & 0.7567 & 0.3860 & 0.1531 & 0.6740 \\
\cline { 2 - 5 } Bootstrap LR Test for India & 2.0208 & 0.3520 & 3.3124 & 0.2070 \\
\hline
\end{tabular}

In the presence of structural changes, parameters in above VAR models estimated using full-sample data from China and India will shift with time. The causal relationship between EPU and stock returns will accordingly be unstable. Therefore, the full-sample causality tests with assumptions of parameter constancy and a single causal relationship across the whole sample period are no longer reliable, and the ensuing results turn to be meaningless (Zeileis et al., 2005). For this reason, this paper proceeds to test for parameter stability and to determine whether structural changes exist. As mentioned before, we uses the Sup-F, Mean-F and Exp-F tests developed by Andrews (1993) and Andrews and Ploberger (1994) to investigate the temporal stability of parameters in the above VAR models formed by the growth rates of EPU and stock prices. The $L_{c}$ test of Nyblom (1989) and Hansen (1992) is also used to test for all parameters in the overall VAR system.

The corresponding results are reported in Table 3 panel $\mathbf{a}$ and $\mathbf{b}$. The Sup-F tests under the null hypothesis of parameters constancy against a one-time sharp shift in parameters are reported in the first row. The results suggest that a one-time sharp shift exists in the stock returns equation consisting of the Indian data. The Mean-F and Exp-F tests under the null hypothesis that parameters follow a martingale process against the possibility that the parameters might evolve gradually are reported in the second and third rows respectively. The results show that parameters in the stock returns equation and VAR (1) system formed by the Chinese data evolve gradually with time, as well as parameters in the stock returns equation consisting of the Indian data. The $L_{c}$ statistics test against the alternative that the parameters follow a random walk process proposed by Gardner (1969), indicative of parameters 
non-constancy in the overall VAR models estimated using the full-sample data of China. As a consequence, these results provide robust evidence that the parameters of the estimated VAR models using full-sample data show short-run instability ${ }^{5}$.

Table 3a: Parameter Stability Tests for China

\begin{tabular}{|c|c|c|c|c|c|c|}
\hline & \multicolumn{2}{|c|}{ EPU Equation } & \multicolumn{2}{|l|}{ SR Equation } & \multicolumn{2}{|c|}{$V A R$ (1) System } \\
\hline & Statistics & $\begin{array}{l}\text { Bootstrap } \\
p \text {-value }\end{array}$ & Statistics & $\begin{array}{l}\text { Bootstrap } \\
p \text {-value }\end{array}$ & Statistics & $\begin{array}{l}\text { Bootstrap } \\
p \text {-value }\end{array}$ \\
\hline Sup-F & 5.58 & 0.72 & 11.91 & 0.11 & 15.78 & 0.19 \\
\hline Mean-F & 1.61 & 0.82 & $6.95^{* *}$ & 0.03 & $9.58^{*}$ & 0.07 \\
\hline $\operatorname{Exp}-F$ & 0.98 & 0.83 & $4.32^{* *}$ & 0.05 & 5.71 & 0.13 \\
\hline$L_{c}^{b}$ & & & & & $1.51^{*}$ & 0.09 \\
\hline \multicolumn{7}{|c|}{$\begin{array}{l}\text { Notes: We calculate } p \text {-values using } 2,000 \text { bootstrap repe } \\
{ }^{*}, * * \text { and }{ }^{* * * *} \text { denote significance at } 10,5 \text { and } 1 \text { percent, } \\
{ }^{\mathrm{b}} \text { Hansen-Nyblom parameter stability test for all par } \\
\text { Table 3b: Parameter Stability Tests for India }\end{array}$} \\
\hline & \multicolumn{2}{|c|}{ EPU Equation } & \multicolumn{2}{|c|}{ SR Equation } & \multicolumn{2}{|c|}{ VAR (2) System } \\
\hline & Statistics & $\begin{array}{l}\text { Bootstrap } \\
p \text {-value }\end{array}$ & Statistics & $\begin{array}{l}\text { Bootstrap } \\
p \text {-value }\end{array}$ & Statistics & $\begin{array}{l}\text { Bootstrap } \\
p \text {-value }\end{array}$ \\
\hline Sup-F & 10.83 & 0.46 & $18.33^{* *}$ & 0.05 & 16.50 & 0.60 \\
\hline Mean- $F$ & 4.67 & 0.49 & $8.94^{* *}$ & 0.05 & 8.64 & 0.64 \\
\hline $\operatorname{Exp}-F$ & 3.43 & 0.37 & $6.45^{* *}$ & 0.04 & 5.65 & 0.59 \\
\hline$L_{c}^{b}$ & & & & & 1.26 & 0.50 \\
\hline
\end{tabular}

Notes: We calculate $p$-values using 2,000 bootstrap repetitions.

${ }^{*}{ }^{* * *}$ and ${ }^{* * *}$ denote significance at 10,5 and 1 percent, respectively.

${ }^{\mathrm{b}}$ Hansen-Nyblom parameter stability test for all parameters in the VAR (2) jointly.

The two variables, EPU and stock prices, are both $I(1)$ processes indicated by the results of $M Z_{a}$ and $K P S S$ unit root tests. This implies that the VAR models formed by the variables in their first differences are misspecified when the cointegration exists. Therefore, tests for cointegration and parameters stability of the long-run relationship should be conducted in the

\footnotetext{
${ }^{5}$ For more detailed examinations, a statistically significant structural break has been identified in 1999: 05 for China and in 2007:09 for India using Sup-F, Mean-F and Exp-F tests developed by Andrews (1993) and Andrews and Ploberger (1994). For India, economic downturn caused by the subprime crisis and subsequent global financial crisis has led to an overall higher economic policy uncertainty since 2007:09, while in 1999:05 the state council of China approved six main policies, such as the reform of stock issuing system and allowing a part of qualified security companies to issue short-term financing bonds, which has greatly sped up China's stock market construction. The structural change in economic conditions or institutional improvement can impose important impacts on the relationship between EPU and stock market performance for India and China.
} 
following step. Specifically, the $F M-O L S$ estimator is used to estimate cointegration and the Sup-F, Mean-F and Exp-F tests, as well as the $L_{c}$ test are used to test parameters stability of the long-run relationship. The related results are presented in Table $\mathbf{4}$ panel $\mathbf{a}$ and $\mathbf{b}$. According to the bootstrap $p$-values in the second row, the $L_{c}$ statistics reject the null hypothesis of cointegration at 1 percent significance level, and meanwhile the sup- $F$ statistics reject the null hypothesis of parameters constancy at 1 percent significance level. Although gradual shifting of parameters in the cointegration equation cannot be identified from the Mean-F and Exp-F tests, significant evidence of a one-time shift in the long-run relationship and hence no reliable cointegration between EPU and stock returns for China and India can be obtained from the $L_{c}$ and sup-F tests.

Table 4a: Parameter Stability Tests in Long-run Relationship for China

\begin{tabular}{|c|c|c|c|c|}
\hline & Sup-F & Mean-F & $\operatorname{Exp}-F$ & $L_{c}$ \\
\hline $\mathbf{S P}=\alpha+\beta * \mathbf{E P U}$ & $316.40^{* * * *}$ & 138.29 & 153.33 & $13.65^{* * * *}$ \\
\hline Bootstrap $p$-value & $<0.01$ & 1.00 & 1.00 & 0.01 \\
\hline
\end{tabular}

Table 4b: Parameter Stability Tests in Long-run Relationship for India

\begin{tabular}{|c|c|c|c|c|}
\hline & Sup-F & Mean-F & $\operatorname{Exp}-F$ & $L_{c}$ \\
\hline $\mathbf{S P}=\alpha+\beta^{*} \mathbf{E P U}$ & $423.48^{* * *}$ & 149.56 & 207.64 & $8.86^{* * * *}$ \\
\hline Bootstrap $p$-value & $<0.01$ & 1.00 & 1.00 & $<0.01$ \\
\hline
\end{tabular}

Based on the above parameters stability tests, both the short-run and long-run parameters in the VAR models estimated using full-sample data show instability because of structural changes and hence the result of absence of any full-sample causality between EPU and stock returns for China and India is meaningless. What's more, absence of cointegration implies that the VAR models in growth rate form are not misspecified. Therefore, the VAR models in Eq. (2) can serve as a basis framework in which we continue to perform the rolling-window causality test with sub-sample data. The employed rolling-window estimation takes structural changes into account and allows the causal links between variables to be time-varying across different sub-samples, which greatly differ from existing literature. 
Utilizing the $R B$ based modified- $L R$ causality tests with the null hypothesis that the EPU does not Granger cause stock returns and vice versa, the bootstrap $p$-values of $L R$-statistics are estimated from the VAR models in Eq. (2) using the rolling sub-sample data including 24-months observations ${ }^{6}$. Besides, the magnitude of the effect of EPU on stock returns and that of stock returns on EPU are also calculated for China and India. All the rolling estimates for each sub-sample are plotted in Figures 1 to 4. After trimming 24-months observations from the beginning of the full sample, these rolling estimates move from 1997:02 to 2013:02 for China and from 2005:02 to 2013:02 for India.

Figure 1 panel a, presents the rolling bootstrap $p$-values of $L R$-statistics estimated using sub-samples data from China. The null hypothesis that EPU does not Granger cause stock returns can be rejected at 10 percent significance level for China. Therefore, the p-values greater than 0.1 (the part above the red line) are ignored to protect against low power results. Figure 1 panel $\mathbf{b}$, gives the bootstrap estimates of the sum of the rolling window coefficients for the impact of EPU on stock returns in China. Figure 1 panel a, shows that the null hypothesis that EPU Granger causes stock returns in China is rejected at 10 percent significance level in few months from 2002 to 2003. Figure 1 panel b, shows that in these months EPU has a significantly negative impact on stock returns. However, in general, the bootstrap sub-sample rolling estimates in Figure 1 indicate that for China the EPU has quite a weak effect on stock returns; that is, the movements in EPU have low power in explaining stock returns over the past decades. This finding may imply that the gloomy performance in Chinese stock market for recent years needs to look for other clues, such as a declined expectation for economic growth.

\footnotetext{
6 Though an interpretation for the selection of 24-month window size has been mentioned earlier, we still implemented different bootstrap rolling-window causality tests using 20-, 30-, 36-month window size and estimated the magnitude of the effect of EPU on stock returns and that of stock returns on EPU. The results are found to be similar to those from the causality test based on 24-month window size, which further indicates that the results based on the latter window size are robust. Specific details of these results are available upon request from the authors.
} 

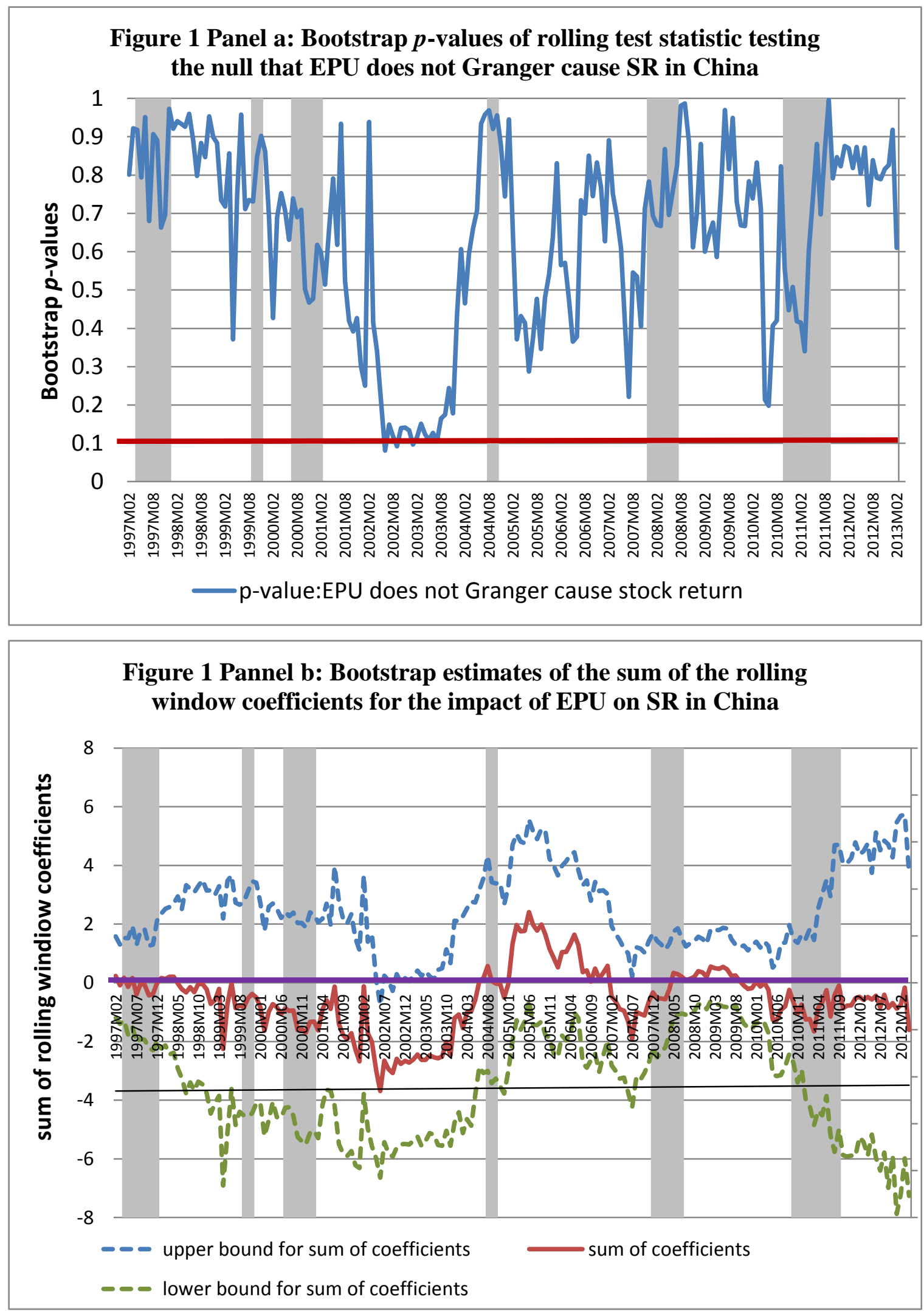

Figure 2 panel a, reports the rolling bootstrap $p$-values of $L R$-statistic with the null hypothesis that stock return does not Granger cause EPU in China. Figure 2 panel b, presents 
the rolling estimates of the magnitude of the effect that stock return has on EPU. According to Figure 2 panel a, the null hypothesis is rejected at 10 percent significance level mainly in the periods from 2003:12 to 2004:09 and from 2006:07 to 2007:02. Moreover, as shown in Figure 2 panel b, stock returns in China have a significantly negative impact on EPU in the period 2003:12-2004:09 when the Chinese stock market experienced a remarkable crash caused by a notable announcement of reducing state-owned shares in state-holding listed companies. However, a positive impact of stock return on EPU can be found in the other period 2006:07-2007:02 when the Chinese stock market performed among the best in the world due to favourable economic conditions, such as high economic growth and abundant capital inflows. These findings demonstrate that for China both the stock market crash and soar would lead to higher economic policy uncertainty. One possible reason is that market crash aggravates economic panic and market soar promotes economic bubble, and under each of the two circumstances government policy changes are expected. Just as Antonakakis et al. (2013) pointed out, an increased volatility in stock market returns lead to increased economic policy uncertainty.

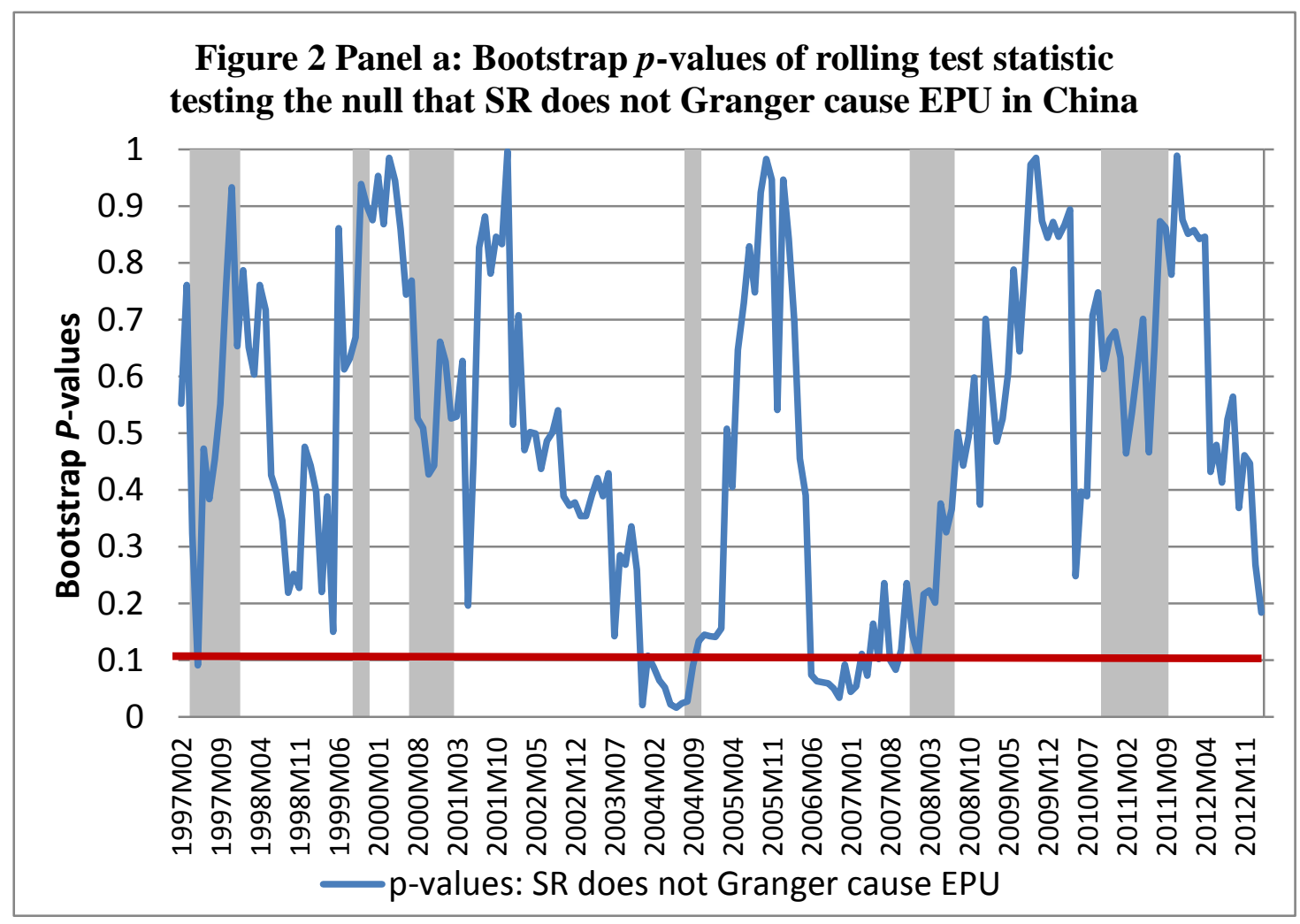




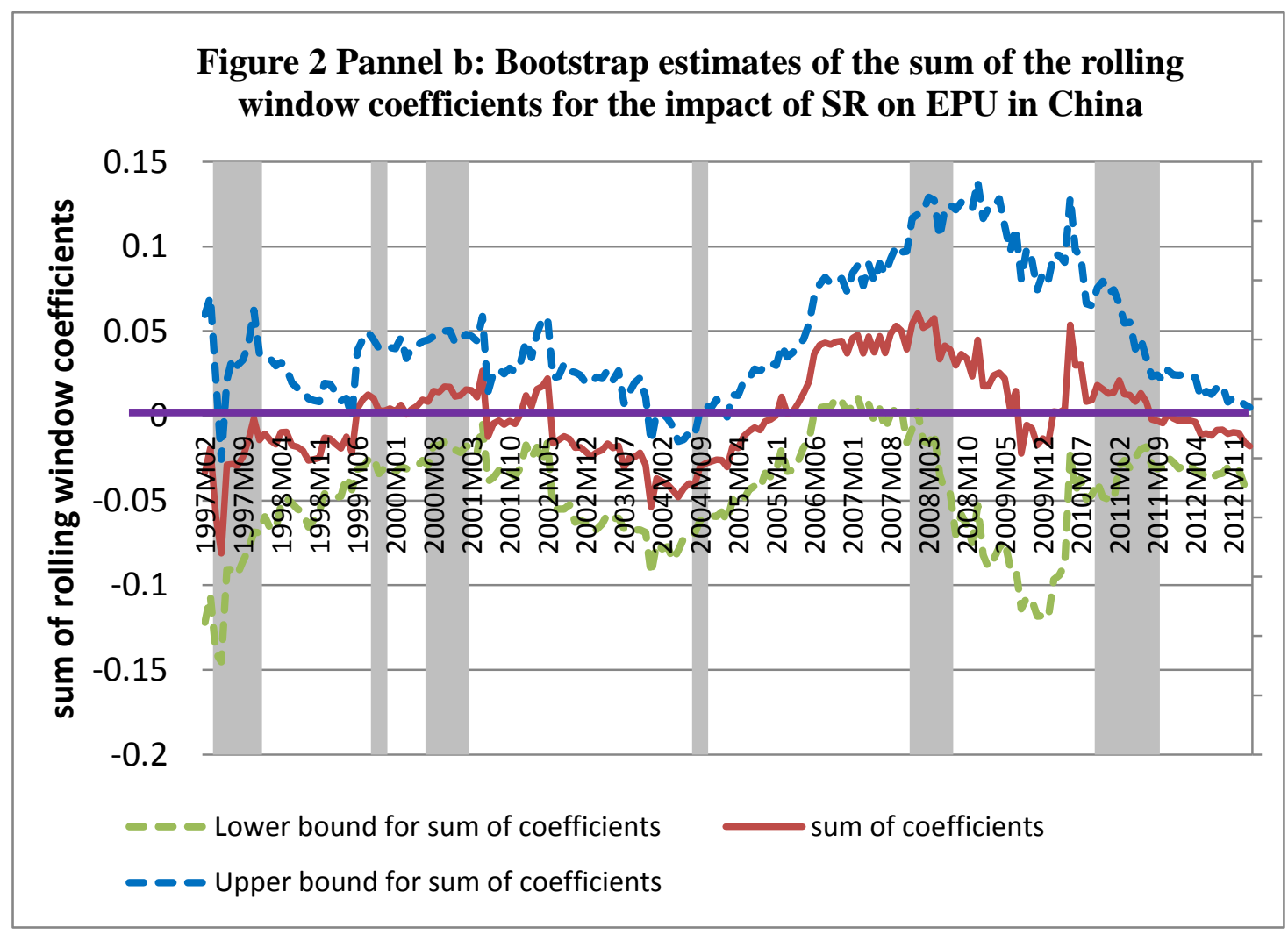

Figure 3 panel a, displays the rolling bootstrap $p$-values of $L R$-statistic with the null hypothesis that EPU does not Granger cause stock return in India. Figure 3 panel b, shows the rolling estimates of the magnitude of the effect that EPU has on stock return. As shown in Figure 3 panel a, the null hypothesis is rejected at 10 percent significance level in the third quarter of 2006 and in the period from 2009:12 to 2010:03. This indicates that EPU has predictive ability for stock return in India during these two sub-periods. However, the significant and negative impact of EPU on stock returns can only be found from Figure 3 panel b, in 2006:Q3. Bhagat et al. (2013) also documented a negative correlation between the Bombay Stock Exchange (BSE) index and EPU for India based on quantile regression. However, though we do find that the change of economic policy uncertainty is the Granger cause of stock return in India, the negative effect of the change in economic policy uncertainty has on stock returns based on the rolling sub-samples estimation in this study is rather weak, much similar to the case of China. 

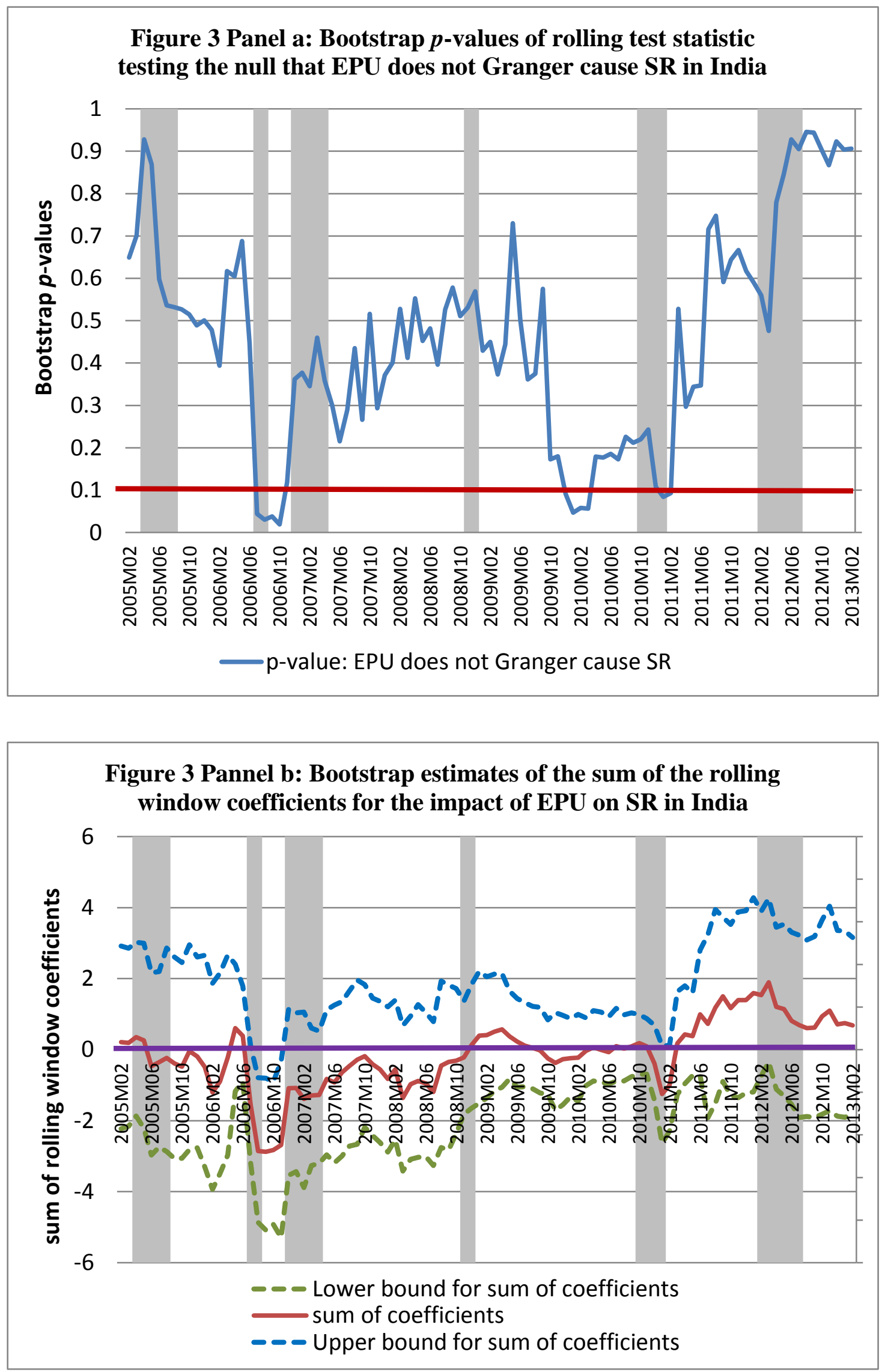
Figure 4 panel a, presents the rolling bootstrap $p$-values of $L R$-statistic with the null hypothesis that stock return does not Granger cause EPU in India. Figure $\mathbf{3}$ panel b, shows the rolling estimates of the magnitude of the effect that stock return has on EPU. Figure 4 panel a, suggests that there have been important changes in the causal link over the sample period. The null hypothesis can only be rejected at 10 percent significance level in the first and third quarters of 2005, indicating that stock return have the ability to explain the movements in EPU during the sub-period. Furthermore, as displayed in Figure 4 panel b, we find stock return imposes a significantly negative effect on movements in EPU in 2005:Q1 when the India's stock market rode an upward trend to hit a series of all-time high. This provides evidence once again that a soaring stock market will increase uncertainty about economic policies. However, in general, the negative effect of stock return on movements in EPU seems to be more common in the case of China as discussed before.

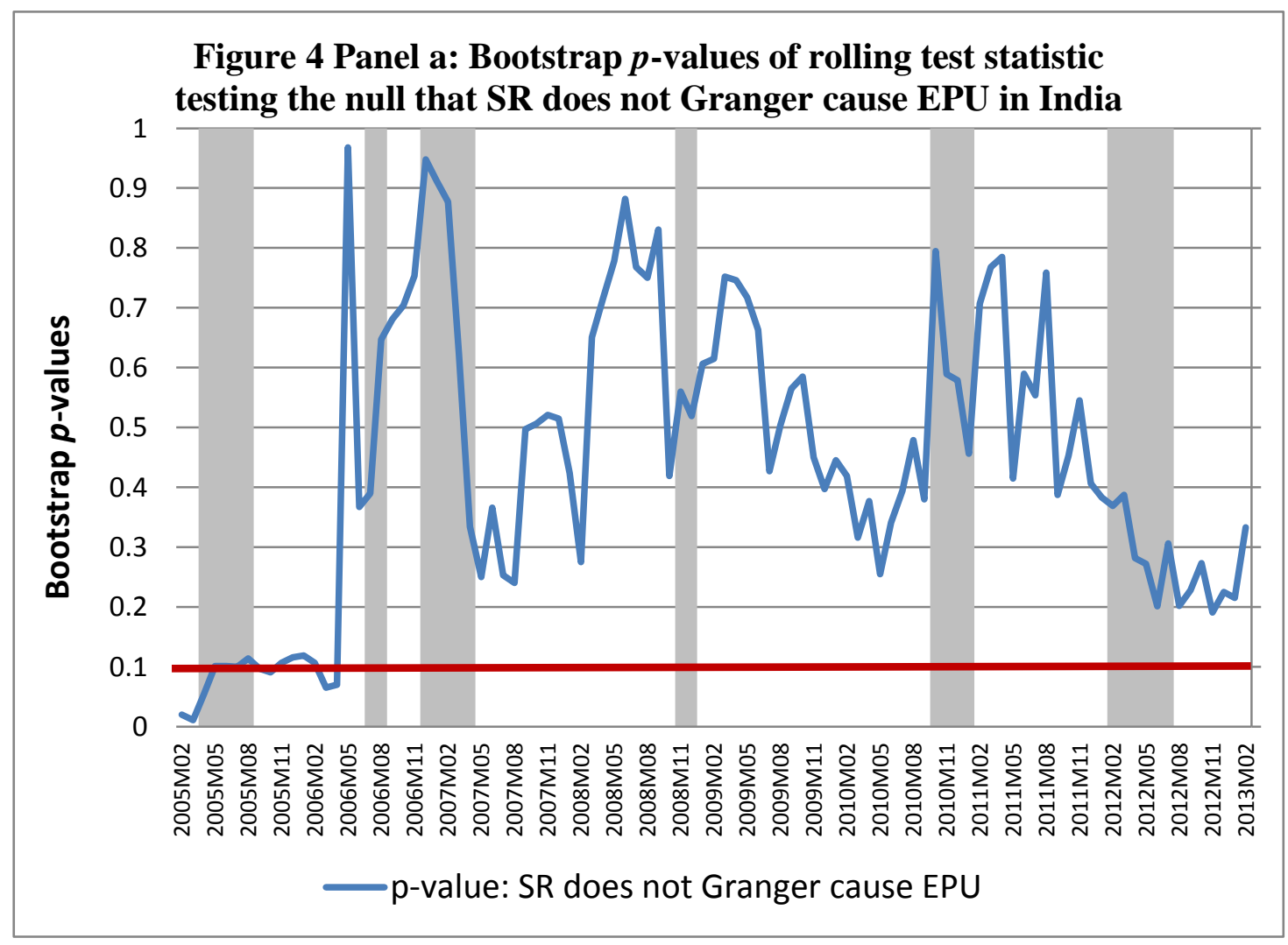




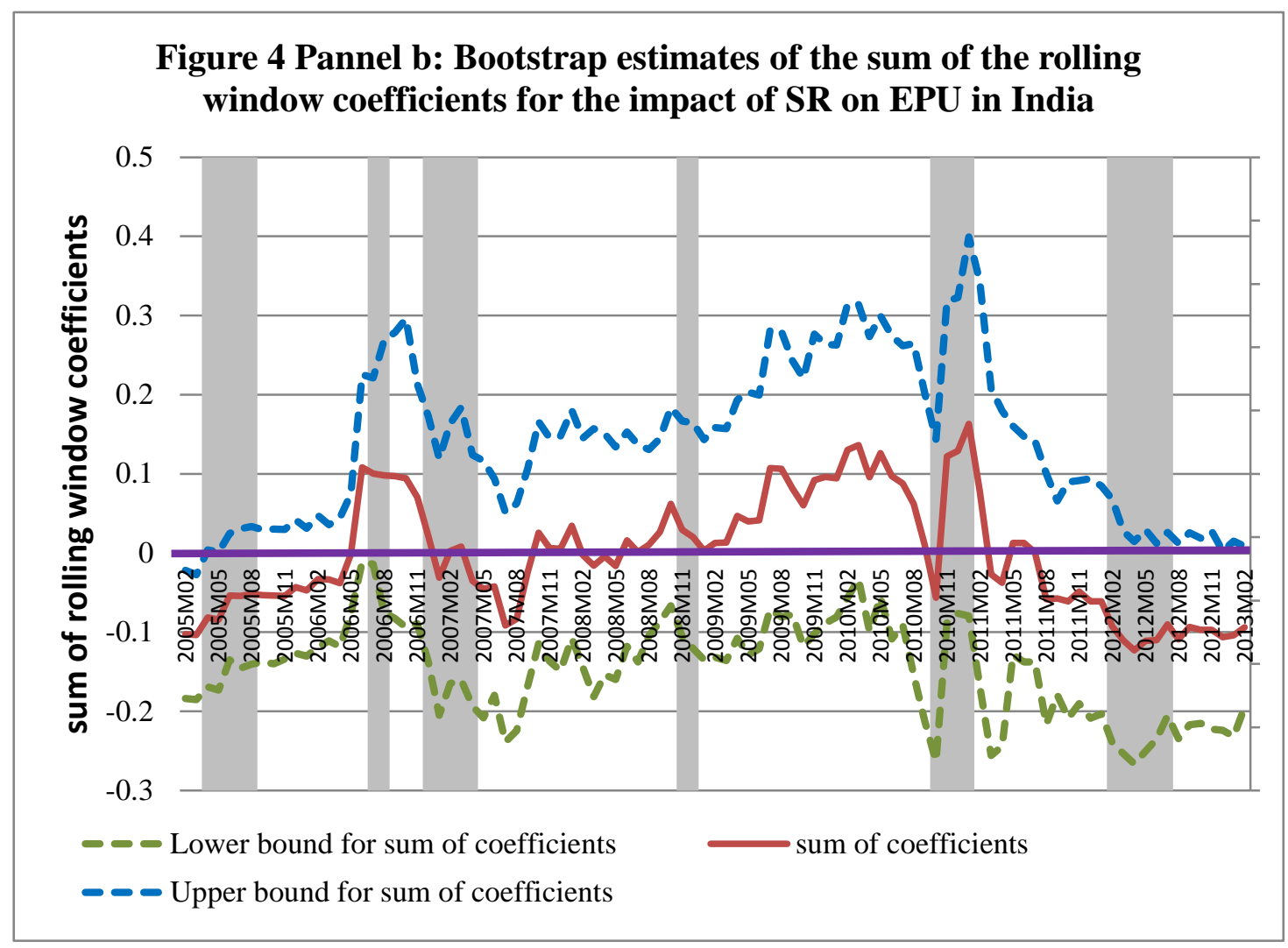

\section{CONCLUSION}

This study investigates the causal relationship between economic policy uncertainty and stock returns using bootstrap full-sample Granger causality test and sub-sample rolling window causality estimation for China and India. The data used in this study are monthly time series data covering the period 1995:02 to 2013:02 for China and 2003:02 to 2013:02 for India. The bootstrap full-sample causality test provides no evidence of any causal relationship between the two series for the two countries. However, taking the presence of structural changes in full-sample data into consideration, parameters stability tests find that both the short-run and long-run relationships between EPU and stock returns for China and India are unstable over the sample period. Therefore, a bootstrap rolling causality test is proposed using sub-samples data with 24-months observations including in each sub-sample. The bootstrap rolling window approach allows the causal relationship between series to be time-varying, instead of assuming that a permanent causal relationship holds over the whole period. 
Using a rolling window of 24 months jointly with the residual-based $(R B)$ bootstrap modified- $L R$ causality test, the rolling $p$-values of the observed $L R$-statistics and the magnitude of the effect that one variable has on the other one are estimated for China and India. Unlike the full-sample causality test results, we do find there are bidirectional causal relationships between stock return and movements in EPU for several sub-periods. That is, the cases of China and India support the bidirectional causality between the two variables. Specifically, the increased change of EPU will negatively impact stock return in the stock markets of China and India. In turn, both the soaring and crashing stock market performance will increase the uncertainty about economic policies for India, and, especially, for China. However, it should be emphasized that the association between EPU and stock returns is, in general, weak in these two emerging countries, even though the overall level of economic policies uncertainty shows an upward trend over the past decades. We cannot simply forecast a downward performance in the stock market according to an increase in uncertainty about economic policy. For the two emerging countries, robust economic growth coupled with favourable economic conditions, such as trade surplus and abundant capital inflows, dominates the stock market performance in China and India. Based on these findings, our paper provides important implications for policy makers and investors:First, uncertainty about economic policies should be reduced by the government to lower potential risks in the stock market, and; second, uncertainty about economic policy should be matched with the fundamentals for proper predictions of stock market performance in China and India.

\section{REFERENCES}

Aizenman, J., Marion, N. (1993). Policy uncertainty, persistence and growth. Review of International Economics, 1 (2), 145-163.

Andrews, D. W. K. (1993). Tests for parameter instability and structural change with unknown change point. Econometrica, 61, 821-856.

Andrews, D.W.K. and Ploberger, W. (1994) Optimal tests when a nuisance parameter is present only under the alternative. Econometrica, 62, 1383-1414. 
Aye, G.C., Balcilar, M., Gupta, R., Jooste, C., Miller, S. M., Ozdemir, Z.A. Fiscal policy shocks and the dynamics of asset prices: The South African experience. Public Finance Review (forthcoming).

Antonakakis, N., Chatziantoniou, I., Filis, G. (2013). Dynamic Co-movements between Stock Market Returns and Policy Uncertainty, Economics Letters, 120 (1), 87-92.

Bernanke, B. S. (1983). Irreversibility, uncertainty, and cyclical investment. The Quarterly Journal of Economics, 98 (1), 85-106.

Bloom, N., Bond, S. Reenen, J. V. (2007). Uncertainty and investment dynamics. Review of Economic Studies, 74, 391-415.

Bloom, N. (2009). The impact of uncertainty shocks. Econometrica, 77 (3), 623-685.

Baker, S., Bloom, N., Davis, S. (2012). Measuring economic policy uncertainty. Stanford working Paper.

Balcilar, M., Ozdemir, Z. A., Arslanturk, Y. (2010). Economic growth and energy consumption causal nexus viewed through a bootstrap rolling window. Energy Economics, 32(6), 1398-1410.

Balcilar, M., Ozdemir, Z. A. (2013). The export-output growth nexus in Japan: A bootstrap rolling window approach. Empirical Economics, 44, 639-660.

Brogaard, J., Detzel, A. (2013). The asset pricing implications of government economic policy uncertainty. Working paper series.

Bhagat, S., Ghosh, P., Rangan, S.P. (2013). Economic policy uncertainty and economic growth in India. Working paper series.

Dixit, A. (1989). Entry and exit decisions under uncertainty. Journal of Political Economy, 97, 620-638.

Dzielinski, M. (2012). Measuring economic uncertainty and its impact on the stock market. Finance Research Letters, 9(3), 167-175.

Granger, C. W. J. (1996). Can we improve the perceived quality of economic forecasts? Journal of Applied Econometrics, 11, 455-73. 
Hacker, R. S., Hatemi-J, A. (2006). Tests for causality between integrated variables based on asymptotic and bootstrap distributions: theory and application. Applied Economics, 38, 1489-1500.

Hansen, B. E. (1992). Tests for parameter instability in regressions with I(1) processes. Journal of Business and Economic Statistics, 10, 321-336.

Johansen, S. (1991). Estimation and hypothesis testing of cointegration vectors in Gaussian vector autoregressive models. Econometrica, 59, 1551-1580.

Kwiatkowski, D., Phillips, P., Schmidt, P., Shin, Y. (1992). Testing the null hypothesis of stationary against the alternative of a unit root: how sure are we that economic time series have a unit root? Journal of Econometrics, 54, 159-178.

Kang, W., Ratti, R.A. (2013). Oil shocks, policy uncertainty and stock market returns. Journal of International Financial Markets, Institutions and Money, 26, 305-318.

Marcus, A. A. (1981). Policy uncertainty and technological innovation. The Academy of Management Review, 6 (3), 443-448.

MacKinnon, J.G., Haug, A.A., Michelis, L. (1999). Numerical distribution functions of likelihood ratio tests for cointegration. Journal of Applied Econometrics, 14, 563-577.

Mantalos, P., Shukur, G. (1998). Size and power of the error correction model cointegration test: a bootstrap approach. Oxford Bulletin of Economics and Statistics, 60, 249-255.

Mantalos, P., 2000. A graphical investigation of the size and power of the granger-causality tests in integrated-cointegrated VAR systems. Studies in Non-Linear Dynamics and Econometrics 4, 17-33.

Nyblom J. (1989). Testing for the constancy of parameters over time. Journal of the American Statistical Association, 84, 223-230.

Ng, S., Perron, P., 2001. Lag length selection and the construction of unit root tests with good size and power. Econometrica, 69, 1519-1554.

Ozoguz, A. (2008). Good times or bad times? Investors' uncertainty and stock returns. Review of Financial Studies, 22 (11), 4377-4422.

Pesaran, M. H., Timmermann, A. (2005). Small sample properties of forecasts from autoregressive models under structural breaks. Journal of Econometrics, 129, 183-217. 
Phillips, P. C. B., Hansen, B. E. (1990). Statistical inference in instrumental variables regression with I (1) processes, Review of Economics Studies, 57, 99-125.

Pastor, L, Veronesi, P. (2012). Uncertainty about government policy and stock prices, Journal of Finance, 67 (4): 1219-1264.

Pastor, L, Veronesi, P. (2013). Political uncertainty and risk premia. CEPR discussion Papers.

Rodrik, D. (1991). Policy uncertainty and private investment in developing countries. Journal of Development Economics, 36 (2), 229-242.

Sims, C. A., Stock, J. H., Watson, M. W. (1990). Inference in linear time series with some unit roots. Econometrica, 58 (1), 113-144.

Shukur, G., Mantalos , P. (1997a). Size and power of the RESET test as applied to systems of equations: a bootstrap approach. Working paper, Department of Statistics, University of Lund, Sweden.

Shukur, G., Mantalos, P. (1997b). Tests for Granger causality in integrated-cointegrated VAR systems. Working paper, Department of Statistics, University of Lund, Sweden.

Shukur, G. and Mantalos, P. (2000). A simple investigation of the Granger-causality test in integrated-cointegrated VAR Systems. Journal of Applied Statistics, 27, 1021-1031.

Sum, V. (2012a). The impulse response functions of stock market returns to economic policy uncertainty. International Review of Applied Financial Issues and Economics (forthcoming).

Sum, V. (2012b). Economic policy uncertainty and stock market performance: evidence from the European Union, Croatia, Norway, Russia, Switzerland, Turkey and Ukraine, Journal of Money, Investment and Banking, 25, 99-104.

Sum, V. (2012c). The reaction of stock markets in BRIC countries to economic policy uncertainty in the United States. Working paper series.

Sum, V. (2012d). The ASEAN stock market performance and economic policy uncertainty in the United States. Working paper.

Toda, H. Y., Phillips, P. C. B. (1993). Vector autoregressions and causality. Econometrica, 61, 1367-1393. 
Toda, H. Y., Phillips, P. C. B. (1994). Vector autoregression and causality: a theoretical overview and simulation study. Econometric Reviews, 13, 259-285.

Toda, H. Y., Yamamoto, T. (1995). Statistical inference in vector autoregressions with possibly integrated processes. Journal of Econometrics, 66, 225-250.

Zeileis A, Leisch F, Hornik K, Kleiber C. (2005). Monitoring structural change in dynamic econometric models. Journal of Applied Econometrics, 20, 99-121. 


\section{Appendix 1: Growth Rates of EPU and Stock Returns}


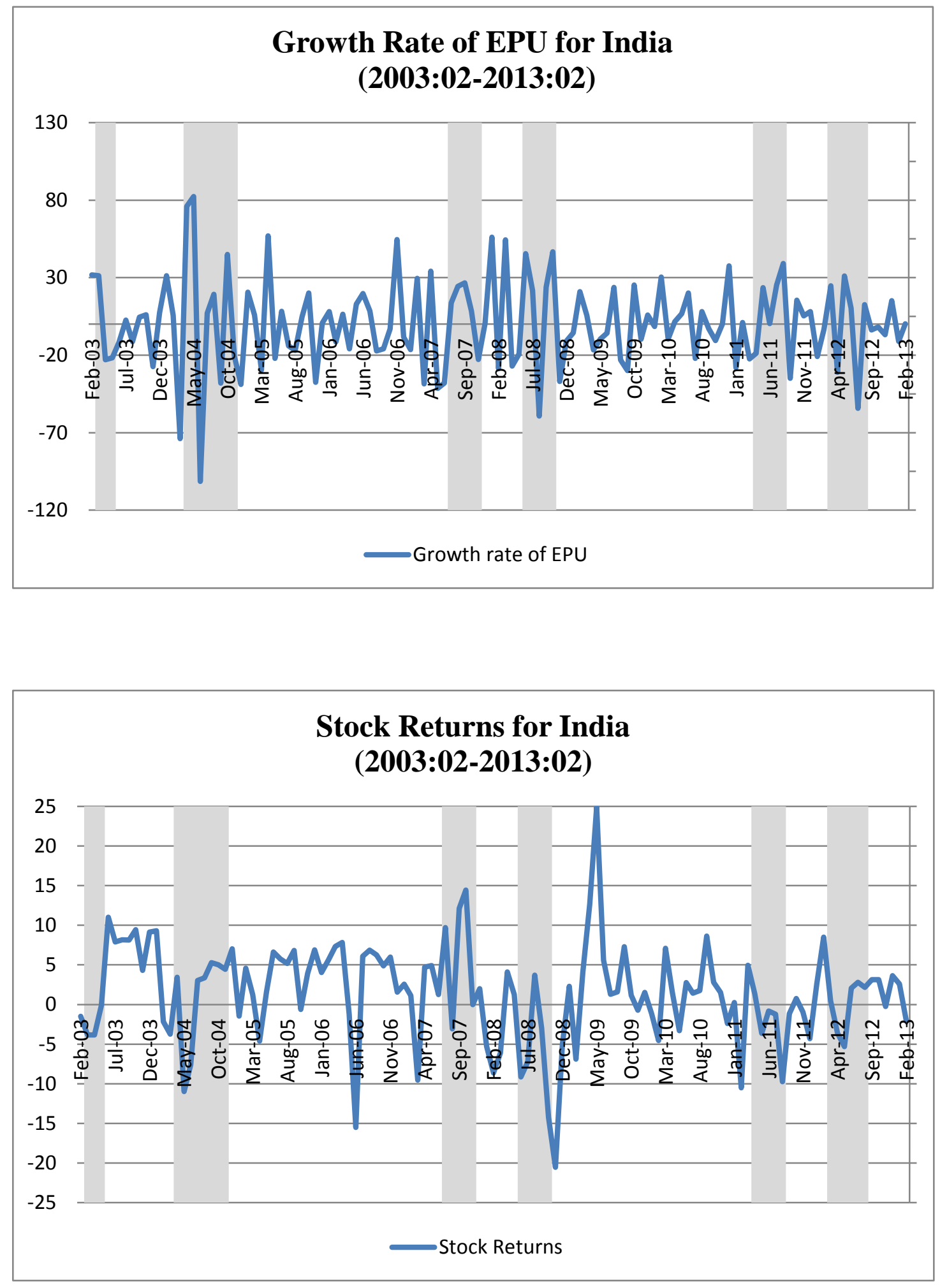